\title{
Enlightening the Effects of Premature Birth on Dental and Orofacial Development: A Review
}

\author{
Anisha Bag ${ }^{1}$, Khooshbu Gayen ${ }^{2}$, Rajib Sikdar $^{3}$, Supreet Shirolkar ${ }^{4}$, \\ Subir Sarkar5, Somen Roychowdhury ${ }^{6}$ \\ ${ }^{1,2,3,4}$ Post Graduate Trainee 3rd Yr, Department of Pedodontics and Preventive Dentistry, Dr R Ahmed Dental \\ College and Hospital, Kolkata \\ ${ }^{5}$ Professor and HOD, Department of Pedodontics and Preventive Dentistry, Dr R Ahmed Dental College and \\ Hospital, Kolkata \\ ${ }^{6}$ Professor, Department of Pedodontics and Preventive Dentistry, Dr R Ahmed Dental College and Hospital,
} Kolkata

Corresponding Author: Supreet Shirolkar

\begin{abstract}
Preterm births are which occur prior to 37 weeks gestation and in developed Western nations it comprises approximately 6 per cent of all live births. Along with having many serious medical problems, it has been hypothesized that the development of oral tissues may get affected in the neonatal period. In preterm children, a high prevalence (around 40-70\%) of generalized enamel hypoplasia had been found in previous studies in the primary dentition and it is plausible to be associated with low bone mineral stores. Other than enamel hypoplasia, crown dilacerations, and palatal distortions are other defects that are frequently observed in preterm children which are usually associated with traumatic laryngoscopy and prolonged endotracheal intubation. The incidence of ECC (International Caries Detection and Assessment System: ICDAS $\geq 2$ ) was also found to be high in low birth weight children. The etiology behind this is multifactorial but maternal factors, maternal factors might play the role of contributing factors. The current review would analyse the dental anomalies in preterm children in depth which might have significant implications in monitoring possible anomalies and in treatment intervention can be done at an early stage.
\end{abstract}

Keywords: Premature birth, Very low birth weight, Dental defects, Enamel hypoplasia.

\section{INTRODUCTION}

As per definition given by the World Health Organization (WHO), a premature birth is one that occurs before 37 weeks of gestation ${ }^{1}$. Previously, birth weight of an infant was considered as an index of prematurity. According to that, premature infants are categorised into 3 groups, which are as follows: Low Birth Weight $(2500 \mathrm{~g})$; very low birth weight VLBW (1500 g); and extremely low birth weight ELBW (1000 g). But recent era find it more accurate to use the ultra-sonographically determined gestational age as the maturity index of infants. Now, by calculating the length of respective gestational period of newborns at birth, infants are called as preterm (PT) if they are born in between 33-36 weeks, very PT (VPT)-when born in between 2932 weeks, and extremely PT (EPT) if born at or before the 29th gestational weeks. ${ }^{2}$ Frequency of preterm delivery is approximately 15 million worldwide and even more in developing countries. ${ }^{3}$ Studies in India, claimed that incidence of preterm labour and preterm delivery are $23.3 \%$ \& 10-69\% respectively. ${ }^{4}$ The etiology behind this is multifactorial and might be explained by maternal factors $(14 \%)$ or by fetal genetic factors (11\%) but in 50\% of the cases, the particular etiological factors are unknown. ${ }^{5}$ Most registered cases are either 
due to multiple pregnancy, low socioeconomic status, misuse of substances, and infection during 1 st trimester or hypertensive diseases of mother. ${ }^{6}$

Intrauterine restricted growth \& prematurity often cause death to the newborn. ${ }^{7}$ Infants born at the lower limit of viability both in terms of gestational age and birth weight have the highest mortality \& morbidity rates. ${ }^{1}$ Although, the mortality rate has been improved with advancement of medical science over the last few decades, infants with premature birth become vulnerable to many complications like respiratory distress syndrome, chronic lung disease, a compromised immune system, cardiovascular disorders, necrotising enterocolitis, hearing and vision problems or neurological deficit ${ }^{8}$. Most of them sustain lifelong $\&$ make impact on the growth, and development of preterm infants. To overcome all these acute consequences, they are often shifted to Neonatal Intensive Care Unit (NICU) to ensure survival, where support is given by assisted ventilation, intubation to combat respiratory distress, epinephrine \& volume expanders for resuscitation or orogastric/nasogastric tube feeding due to insufficient sucking reflex during their early days ${ }^{9}$. All these chronic medical needs make the fragile organs more vulnerable to damage. So, the significance of preterm morbidity in postnatal development is two folds. 1 st is due to the complications of prematurity and $2 \mathrm{nd}$ is the consequences of initial invasive treatment protocols during the perinatal and neonatal periods.

Like other systems in body, the oral structures are not spared from the ill-effects of birth prematurity. Flowchart 1:Represents oral complications in preterms \& their potential causes
Flowchart no.1:- Oral complications in preterm and their potential causes

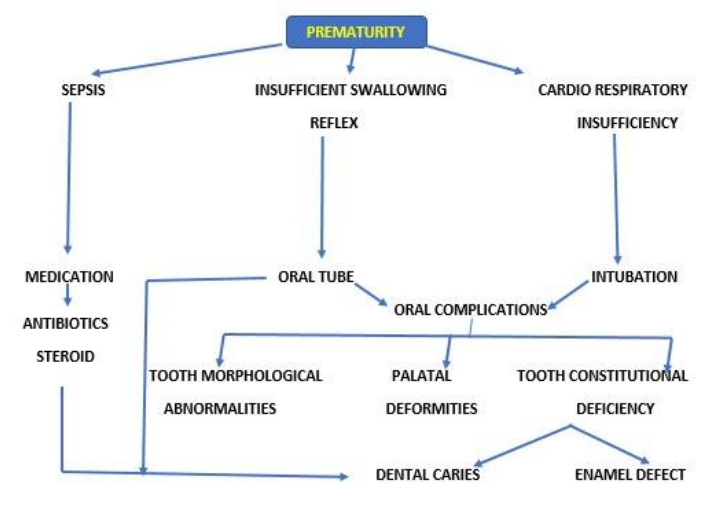

\section{Enamel defects}

Dental enamel is a unique tissue with no remodelling capability once formed. So, any insult during its formative stage is permanently registered on the surface of enamel. The formative phase is a long period of time starting from $2^{\text {nd }}$ trimester IU (primary central incisor formation) to approx. 18 years of life postnatally $\left(3^{\text {rd }}\right.$ molar emergence) ${ }^{10}$. Broadly this formative phase can be divided into 3 phases-matrix formation, calcification \& maturation, insults occurring at any of these phases bring about enamel surface defects ${ }^{11}$. The extent of defect depends upon the intensity of defects and stage of formation. Grossly it has been postulated that impact at an early phase causes quantitative defects whereas disturbances during later phases results in qualitative defects. So, clinically represents as enamel hypoplasia or as opacity. Enamel hypoplasia is described as quantitative deficiency occurring on enamel as pits, grooves or large missing portion. Enamel opacity represents qualitative change like translucent enamel ${ }^{12}$.

Association among preterm birth and enamel defects may be due to systemic malformation or localized disturbances. Imbalance in calcium homeostasis has been reported as one of the causative factors in enamel defects ${ }^{13}$. Studies have shown a strong correlation between neonatal hypocalcaemia and enamel hypoplasia. Infant's body stores maximum Calcium and 
phosphorus majorly during $3^{\text {rd }}$ trimester of gestation. So preterm infants or extremely low birth infants fail to accumulate these stores as they born short of gestational age $^{14}$. Biomedical complication of mother like diabetes mellitus, placental insufficiency, and dietary deficit of calcium also contribute to in utero imbalance. Risks are further enhanced by repeated episodes of fever, malnutrition, infections (sepsis), serious medical conditions (hypoxia, hyperbilirubinemia) and use of medications during early neonatal phase ${ }^{15}$. Chemical analysis when done in primary teeth revealed that the surface enamel content of calcium/carbon was comparatively lower in preterm infants, thus making the enamel more porus ${ }^{16}$.

Localized trauma during early stage may also cause enamel defects. Oral intubation/mechanical ventilation may cause inadvertent force to the developing maxilla and surrounding teeth. Seow et al demonstrated in their study that infants with history of intubation had more enamel defects on left maxillary teeth compared to non-intubated one ${ }^{10}$.Prevalence of enamel defects among preterm/VLBW infants is in a range of $43 \%-96 \%$, which is quite high. Teeth that mostly involved are the primary incisors, canines and first molars ${ }^{17}$. Previously it had been told that enamel defects are limited to the primary dentition only, as the permanent teeth have not yet begun their formation at the time of the preterm birth. However, recent studies have confirmed that persistent metabolic disturbances after birth may initiate disturbance in mineralisation of the permanent dentition also ${ }^{18}$.

A study done by Aline et al comparing 32 preterm infants with 64 term peer showed enamel defects are high both in primary and permanent teeth in the former group $^{19}$. Seow found more enamel opacities in permanent molars \& lateral incisors in VLBW infants in comparison with controls $^{20}$.

Clinical importance of these surface defects is not only limited to esthetic compromisation, it may favour plaque accumulation to caries formation, if left untreated results in tooth loss also ${ }^{21}$.

\section{Hypoplasia-associated early childhood caries (HAS-ECC)}

Early childhood caries is seen in a child less than 71 months or less with presence of one or more cavitated or non cavitated lesion, missing or filled teeth due to caries $^{22}$.studies have found significant association between low birth weight and dental caries ${ }^{23}$. The development of enamel hypoplasia and the colonization of cariogenic bacteria predispose them to $\mathrm{ECC}^{24}$. Growth retardation during intra uterine period also causes deficient cellmediated immunity in preterm infants that supposed to cover from infection till $1^{\text {st }}$ birthday. It has been shown that preterm children with defective immune system are more susceptible to get infected by cariogenic bacteria like streptococcus mutans due to extended period of infectivity that may persist upto 5 years ${ }^{25}$. When levels of salivary $\operatorname{IgA}$ in premature infants were compared with the term peer, it showed approximately 2.5-fold deficit in the former $^{26}$. Moreover preterm neonates do not generate enough sucking pressure so often relies on formula milk (more sugar content) through tube feed/gavage feeding instead of breast-feeding (more nutrition, less sugar) ${ }^{27}$. Frequently, they are prescribed enteral medications containing high percentage of sucrose or acids during neonatal time, promote the acidogenic and cariogenic flora to establish themselves in oral environment ${ }^{28}$ and all these predisposes the infants to early childhood caries. ${ }^{29}$

Jaw bone deformities-preterm infants often have suboptimal bone mineralization due to short gestational age, extended parenteral route of nutrition; prolong period of immobilization, complications like infection, cerebral palsy, pulmonary insufficiency or drug side-effects essential for neonatal survival like corticosteroids ${ }^{30}$. Long term bony side effects in preterm children have been 
investigated, though results are inconclusive. Study on mandibular cortical width between term \& preterm did not show much difference, probably due to the fact that neonates in NICU often have intense mineral supplements along with parenteral feeding ${ }^{31}$ leads to upliftment of bone mineral contents. But, during early stages of life bones are usually malleable and pressure from any object can easily distort its shape. Palate may be influenced by number of factors like mode of delivery, positioning, prolong oral intubation, absence of adequate sucking response, delay in tooth eruption or inadequate muscle tonicity etc ${ }^{32}$. Altered palatal morphology of preterm children may include asymmetry, posterior narrowing, increased anterior tilt, greater depth and palatal grooves. Ill-effect of prolonged orotracheal intubation have been postulated to cause palatal deformation ${ }^{33}$. Stiffness of tube \& length of tubing period, position of tube may affect differently, generally the incidence of Palatal grooving has been reported with a frequency of $17 \%$ to $87 \%$ in preterm infants ${ }^{34}$. Through catch up growth palatal defect may get remodelled in the later stage but some of these defects may persist till late childhood causing palatal asymmetry, speech impairment, hypernasality etc ${ }^{35}$.

\section{Tooth maturation/ eruption \& shape alteration:}

Growth in overall body remains symmetrical with dental development. Usually, the primary teeth start to develop from middle of the gestation period until the infant completes one year of his life. If we compare preterm child with his term peer then we can appreciate that maturation of teeth does not differ significantly but eruption of primary teeth may vary ${ }^{36}$. Factors that enhance the prevalence of delayed tooth eruption are short length of gestational span, low birth weight of infants and associated neonatal factors like, complications, systemic immaturity, long history of oral intubation, average weight gain/day, etc ${ }^{37}$. Local traumatic forces generated from laryngoscopy and endotracheal intubation may render dilacerations of the tooth crown in some cases of pre term children. ${ }^{38}$

\section{Dental intervention:}

- To ensure effective feeding \& patency of airway neonates often require use of orogastric, orotracheal tubing. ${ }^{39}$ Prolonged use of both them might cause iatrogenic problems like palatal grooving, tracheal/laryngeal mucosal injury and infection ${ }^{40}$. For this an intra-oral appliance with anterior and posterior groove can be used to stabilize these tubes and to reduce above mentioned complications ${ }^{41}$. Frequent appliance fabrication is needed as the infant's head grows by $2.5 \mathrm{cms}$ circumferentially \& prolong intubation $^{42}$. So, pedodontists can easily make these appliances \& reline them when required with great ease. Further investigation is needed whether a flexible yet steady material can be used instead of acrylic material during appliance fabrication which decreases the need for frequent relining.

- Anticipatory guidance-it holds an important part in early professional dental intervention of an infant. it should be conducted within 6 months of the infant's life, but no less than 12 months of age $^{43}$.it provides relevant information to the caregiver regarding how to improve a preterm infant's life-by giving proper diet knowledge, nurturing of preterm neonates, oral hygiene maintenance, effects of non-nutritive oral habits or caries prevention measures available etc ${ }^{44}$.

- Caries control protocol - as discussed above preterm infants are in great risk of developing dental caries due to multiple reasons ${ }^{45}$. So, 
caries risk assessment ${ }^{46}$, diet monitoring followed by preventive protocols for infants should be given importance to enhance quality of life. Fluoride varnish application ${ }^{47}$, sealants or SS crown can be given for high risk preterm infants. If enamel defects are detected, it is advisable to apply topical fluoride along with (CPP-ACP) to promote surface remineralization ${ }^{48}$.

- Help in generating quick sucking reflex- Due to incapability to produce effective sucking, preterm \& very low birth weight infants often require enteral nutritional support (tube feeding) ${ }^{49}$ since birth. Long term tube feeding leads to potential tube dependency \& lack of intention towards natural oral intake $^{50}$. This transition from tube feeding to oral eating is important for infants' nutrition \& neurodevelopment ${ }^{51}$. So, oral stimulation programme should be generated at NICU as early as possible ${ }^{52}$. In developing countries like India due to shortage of medical personnel per person usually nurses do the stimulation procedures, which may be insufficient. So health care providers should be included in multi-disciplinary team to establish correct orofacial physiology \& monitor oral growth ${ }^{53}$.

- Orthodontic correction for retained palatal deformities.

\section{CONCLUSION}

Preterm birth is one of the indicators of compromised health and delayed development of infants. It might get overcome to some extent by catch up growth over a period of 2-3 years, mostly remain less than full term peers. Compromised oral health can't give better body. So, dental check-up for preterm infants should be started as soon as they are shifted to NICU for better manipulation of oral structure, when guidance is provided to the caregiver at an early stage by oral health care professional awareness followed by assurance increase. A multidisciplinary team consist of paediatrician, pedodontists, speech therapist; trained nurses can approach an early bird more systematically $\&$ age appropriately.

\section{Acknowledgement: None}

Conflict of Interest: None

\section{Source of Funding: None}

\section{REFERENCES}

1. WORLD HEALTH ORGANIZATION (WHO). International Statistical Classification of diseases and related health problems. Geneva(Switzerland): WHO, 2004.

2. Stjernqvist K, Svenningsen NW. Ten-year follow-up of children born before 29 gestational weeks: health, cognitive development, behaviour and school achievement. Acta Paediatr. 1999; 88:557562.

3. Preterm birth. Who.int. https://www.who.int/news-room/factsheets/detail/preterm-birth. Published 2021. Accessed August 21, 2021.

4. McPheeters ML, Miller WC. Hartmann KE et al. The epidemiology of threatened preterm labor: a prospective cohort study. Am J Onstet Gynecol 2005;192;1325-9

5. Usher RH. The special problems of the premature infant. In: Avery GB, ed. Neonatalogy-Pathophysiology and Management of the Newborn. Philadelphia, Pa: Lippincott; 1981:23-261

6. Slattery MM, Morrison JJ: Preterm delivery. Lancet 2002;360:1489-1497.

7. Platt MJ. Outcoms in preterm infants. Public health 2014;128(5):399-403.

8. Institute of Medicine (US) Committee on Understanding Premature Birth and Assuring Healthy Outcomes; Behrman RE, Butler AS, editors. Preterm Birth: Causes, Consequences, and Prevention. Washington (DC): National Academies Press (US); 2007. 10, Mortality and Acute Complications in Preterm Infants. 
9. Lissauer T, Claydon G. Neonatal medicine. In: Lissauer T, Claydon G, eds. Illustrated Textbook of Paediatrics. London, UK:Mosby International Limited; 1997:83100

10. Seow WK: Clinical diagnosis of enamel defects: Pitfalls and practical guidelines. Inter Den J 47:173-182, 1997

11. Lv P, Gao XJ. [Phenotype analysis and the molecular mechanism of enamel hypoplasia]. Beijing Da Xue Xue Bao Yi Xue Ban. 2009 Feb 18;41(1):121-3. Chinese. PMID: 19221580.

12. F'ederation Dentaire Internationale Commission on Oral Health, 'Research and Epidemiology: A review of developmental defects of enamel (DDE) index. Int Dent $\mathbf{J}$ 1992; 42:411-2.

13. Seow WK, Masel JP, Weir C, Tudehope DI. Mineral deficiency in the pathogenesis of enamel hypoplasia in prematurely born, very low birthweight children. Pediatr Dent. 1989; 11:297-302.

14. Eastman D. Dental outcomes of preterm infants. Newborn and Infant Nursing Reviews. 2003;3(3):93-98.

15. Seow WK. Effects of preterm birth on oral growth and development. Aust Dent J. 1997; 42:85-91

16. Rythén M, Sabel N, Dietz W, Robertson A, Norén JG. Chemical aspects on dental hard tissues in primary teeth from preterm infants. European Journal of Oral Sciences. 2010; 118(4):389-95

17. Fearne JM, Bryan EM, Elliman AM, et al: Enamel defects in the primary dentition of children born weighing less than $2000 \mathrm{~g}$. Br Dent J 1990 168:433-437

18. Pimlott JF, Howley TP, Nikiforuk G, et al: Enamel defects in prematurely born, low birth weight infants. Pediatr Dent 1985 7:218-223

19. Aine L, Backstrom MC, Ma ki R, et al: Enamel defects in primary and permanent teeth of children born prematurely. J Oral Pathol Med 2000 29:403-409

20. Seow WK: A controlled study of the development of the permanent dentition in very low birth weight children. Pediatr Dent 1996 18:379-384

21. Johnson D, Krejci C, Hack M, et al: Distribution of enamel defects and the association with respiratory distress in very low birth weight infants. J Dent Res 1984 3:59-64,
22. Tsang AK. The special needs of preterm children-an oral health perspective. Dental Clinics. 2016; 60(3):737-56

23. Lai PY, Seow WK, Tudehope DI, et al: Enamel hypoplasia and dental caries in very-low birth weight children: A casecontrolled, longitudinal study. Pediat Dent 1997 19:42-49

24. Li, Y., Navia, J.M. and Bian, J.Y. (1996) Caries experience in deciduous dentition of rural Chinese children 3-5 years old in relation to the presence or absence of enamel hypoplasia. Caries Res 1996;30:815

25. Chandra, R.K. (2002) Nutrition and the immune system from birth to old age. Eur.

J. Clin. Nutr. 56, S73-S76

26. Nogueira, R.D., Sesso, M.L., Borges, M.C., Mattos-Graner, R.O., Smith, D.J. and Ferriani, V.P. (2012) Salivary IgA antibody responses to Streptococcus mitis and Streptococcus mutans in preterm and fullterm newborn children. Arch. Oral. Biol. 57, 647-653,

27. Perera, P.J., Fernando, M.P., Warnakulasooriya, T.D. and Ranathunga, N. (2014) Effect of feeding practices on dental caries among preschool children: a hospital based analytical cross sectional study. Asia Pac. J. Clin. Nutr. 23, 272-277

28. Oliveira AF, Chaves AM, Rosenblatt A. The influence of enamel defects on the development of early childhood caries in a population with low socioeconomic status: A longitudinal study. Caries Research. 2006; 40(4):296 302.

29. Tsang AK. The special needs of preterm children-an oral health perspective. Dental Clinics. 2016; 60(3):737-56

30. Dokos C, Tsakalidis C, Tragiannidis A, Rallis D. Inside the "fragile" infant: pathophysiology, molecular background, risk factors and investigation of neonatal osteopenia. Clin Cases Miner Bone Metab 2013; 10: 86-90 [PMID: 24133523]

31. Paulsson-Björnsson L, Adams J, Bondemark L, Devlin H, Horner K, Lindh C. The impact of premature birth on the mandibular cortical bone of children. Osteoporos Int. 2015 Feb;26(2):637-44. doi: 10.1007/s00198-014-2898-8. Epub 2014 Sep 30. PMID: 25266484.

32. Saunders BS, Easa D, Slaughter RJ. Acquired palatal groove in neonates. J Pediatr 1976; 89:9889. 
33. Erenberg A, Nowak AJ. Palatal groove formation in neonates and infants with orotracheal tubes. Am J Dis Child 1984; 138:974-5.

34. Monteli RA, Bumstead DH. Development and severity of palatal grooves in orally intubated newborns. Am J Dis Child 1986; 140:357-9.

35. Kopra DE, Davis EL: Prevalence of oral defects among neonatally intubated 3 to 5 and 7 to 10 year old children. Pediatr Dent 13:349-355, 1991

36. Backstrom MC, Aine L, Maki R, Kuusela A-L, Sievanen H, Koivisto A-M, Ikonen RS, Maki M. Maturation of primary and permanent teeth in preterm infants. Arch Dis Child Fetal Neonatal Ed. 2000;83(2):104-108

37. Seow WK, Humphrys C, Mahanonda R, Tudehope DI. Dental eruption in low birthweight prematurely born children: a controlled study. Pediatr Dent. 1988;10(1): $39-42$.

38. Trupkin DP. Eruption patterns of the first primary tooth in infants who were underweight at birth. ASDC J Dent Child. 1974;41:279-282.

39. Gonten AS, Meyer JB, Kim AK. Dental management of neonates requiring prolonged oral intubation. Journal of Prosthodontics. 1995;4(4):222-25.

40. Erenberg A, Nowak A. Appliance for stabilizing orogastric and orotracheal tubes in infants. Critical Care Medicine. 1984;12(8):669-71.

41. Vikas B Kamble, Shital K Shah, Vishnu B Rathod et al. Prosthodontic Approach in Management of Prolonged Neonatal Intubation. J Clin Diagn Res. 2016 Nov; 10(11): ZD19-ZD20. doi: 10.7860/JCDR/ 2016/22408.8863

42. Shimoyama T, Kato T, Horie N, Nasu D, Kaneko T. Oropharyngeal airway appliance for infant with upper airway obstruction: Report of a case. The Journal of Clinical Pediatric Dentistry. 2002;27:25-28.

43. American Academy of Pediatric Dentistry. Guideline on infant oral health care.2014. Clinical Guidelines. p. 141-5.

44. Marcdante KJ, Kliegman RM, Jenson HB, et al. Nelson Essentials of pediatrics.6th edition. Philadelphia: Saunders Elsevier; 2011.

45. Tsang A. K. (2016). The Special Needs of Preterm Children - An Oral Health Perspective. Dental clinics of North America, 60(3), 737-756.

46. Twetman S, Dhar V. Evidence of effectiveness of current therapies to prevent and treat early childhood caries. Pediatr Dent 2015;37(3):246-53

47. Slayton RL. Clinical decision-making for caries management in children: an update. Pediatr Dent 2015;37(2):106-10 [systematic review].

48. Zhou C, Zhang D, Bai Y, et al. Casein phosphopeptide-amorphous calcium phosphate remineralization of primary teeth early enamel lesions. J Dent 2014;42(1):219.

49. Pahsini, K., Marinschek, S., Khan, Z., Urlesberger, B., Scheer, P. J., \& DunitzScheer, M. (2018). Tube dependency as a result of prematurity. Journal of neonatalperinatal medicine, 11(3), 311-316.

50. Ishizaki A, Hironaka S, Tatsuno $\mathrm{M}$, et al. Characteristics of and weaning strategies in tube-dependent children. Pediatr Int. 2013;55(2):208-13.

51. Jadcherla SR, Khot $\mathrm{T}$, Moore $\mathrm{R}$, et al. Feeding methods at discharge predict longterm feeding and neurodevelopmental outcomes in preterm infants referred for gastrostomy evaluation. J Pediatr. 2017;181: 125-30.e1

52. Fucile S, Gisel EG, Lau C. Effect of an oral stimulation program on sucking skill maturation of preterm infants. DevMed Child Neurol. 2005;47(3):158-62.

53. Shalem T, Fradkin A, Dunitz-Scheer M, et al. Gastrostomy tube weaning and treatment of severe selective eating in childhood: Experience in Israel using an intensive three-week program. Isr Med Assoc J. 2016;18(6):331-5.

How to cite this article: Bag A, Gayen K, Sikdar $\mathrm{R}$ et.al. Enlightening the effects of premature birth on dental and orofacial development: a review. Int J Health Sci Res. 2021; 11(9):157163. DOI: https://doi.org/10.52403/ijhsr. 20210924 